\title{
Assessment of the Quality of Life, Health, and Social Wellness in Upper Elementary School Students: Cross-Cultural and Gender Specificity
}

\author{
Ružena Popović $^{1}$, Evdokia Samouilidou ${ }^{2}$, Jasna Popović ${ }^{3}$, Milan Dolga $^{4}$ \\ ${ }^{1}$ University of Niš, Faculty of Sport and Physical Education, Niš, Serbia \\ ${ }^{2}$ School Supervisor for Physical Culture - Northern Aegean Region, Athens, Greece \\ ${ }^{3}$ University of Pristine/Kos.Mitrovica, Faculty of Sport and PE, Leposavić (Kosovo)*, Serbia \\ ${ }^{4}$ Agency for Multivariate Data Analysis, "Smart Line" Novi Sad, Serbia \\ Email: ruzenapop@mail.com
}

\begin{abstract}
:
The objective of this study is a comparative analysis of the possibilities of physical education $(P E)$ inclusion in children with health problems, and the current status in upper elementary school boys and girls. Understanding the concept of impaired health is a precondition for the realization of the training process and possible integration in the process of $P E$, according to the structure of health disadvantages. Method. Quality of life was assessed with the Questionnaire (Q), and analysis was done at three levels, with adequate methods of evaluation. Results. Comparative analysis, regarding the cultural and gender specificities is elaborated, based on MANOVA and DISCRA analysis, within the Introductory part, and 11 scales of the $Q$. Conclusion. Analysis of data points out on the significant cross-cultural differences, considering survey results, with a special overview of total samples of respondents (boys/girls) from diverse cultural, and social backgrounds.
\end{abstract}

Keywords:

school-children; PE; health; questionnaire; cultural / gender comparison

\section{Introduction}

Quality of life, from the contemporary aspect of studying, has an important place in the practice of health care and scientific-research work. He has long been discussed within the framework of social sciences, by sociologists. That quality of life mostly associated with the economic status of individuals and feelings concerning this situation. The quality of life by sociologists mainly means a set of parameters which include the physical and emotional status, vitality, functionality, personal and spiritual fulfillment, the adequacy of housing and nutrition, employment, social integration, social environment and positive support of the social environment (Dictionary of Sociology, 2007:281). In line with this approach, health is only one component of the broader concept.

With the development of society are being modified the indicators of quality of life, so that in addition to economic situation are evaluate psychic values as well (satisfaction, personal development) and community affiliation. The subjective indicators of the quality of life have connection with a feeling, that is, emotional well-being and life satisfaction, while the real situation is assessed with economic indicators.

Large interest within medicine, for the quality of life, is hardened by the development of the science of health and health care, from the moment when the WHO, defined health as "a state of complete physical, mental and social well-being and not simply the absence of disease and disability", according to (Kvrgić, S., 2001:10). 
Although the idea of assessing the quality of life, using various measuring instruments is widely accepted by the researches of different areas, even yet has no unique definition. As a result, the indicators of the quality of life are not clearly defined, but include wide range of different measures, with a little difference between the scales for the assessment of the quality of life, and those for measuring overall health. However, many of authors observe quality of life as a complex function that contains more areas or domains of life and work of individuals, including physical and social function, mental status and type of symptoms, or health problems and individual perception of health.

\subsection{The subject, problem, aim and tasks of research}

The purpose of this pilot study was a comparative analysis of the quality of life of the elementary school students in terms of the possibilities of physical activity application for children with health problems, and the presentation of the current status in the samples of respondents of different groups of ethnic origin (home and foreign country elementary school children).

The key aim, and the problem orientation of this study is related to the analysis of eleven thematic segments $\left(\mathrm{C}_{1-} \mathrm{C}_{11}\right)$, and 37 items/study questions, within the questionnaire $(Q)$, used for the assessment of the Quality of life, regarding Health and Social Wellness (QLHSW) components. The Convention on Children Rights, adopted by the UN (1989), points out that children have a right to health and well-being.

For this reason, the objective of this study is to assess all mentioned components, using a comprehensive $(Q)$. Of the special interest is to assess emotional, and physical components of health, regarding the student's health situation, which may affect their ability to engage in activities of physical education (PE), as well as the perception of social wellbeing. For that reason are set the following tasks, regarding the comparative analysis of the gender differences in home country (HC) sub-samples (boys/girls), as well as different "group's" of ethnic origins (EO) analysis.

1) To present the basic characteristics of items, within eleven segments of $\boldsymbol{Q}$, regarding the opinions of two "groups" of respondents, of different $\boldsymbol{E O}$, with a presentation of possible gender differences in $H C$ sub-samples.

2) To determine the differences in the statements modalities, between two "groups" of different $\boldsymbol{E O}$, concerning the applied items within particular segments of the $\boldsymbol{Q}$, with a presentation of possible gender differences in $\boldsymbol{H C}$ sub-samples.

3) To define the characteristics of each "groups" of respondents of different $\boldsymbol{E} \boldsymbol{O}$, regarding the applied items within the particular segments of $\boldsymbol{Q}\left(\mathrm{C}_{1} \mathrm{C}_{11}\right)$.

4) To determine the contribution of the wholes (C) to the characteristics of the "groups" of different EO: Greece (GRE-1), Serbian (SER-2), on total samples of respondents.

\subsection{Research hypothesis}

Taking into account the previous experience, the basic aim, and the presented problem orientation, objective, and goals of the research, as well as the methodological approach to this study, there was set up a Global hypothesis as null $\left(\mathbf{H}_{\mathbf{0}}\right)$, and alternative $\left(\mathbf{A}_{0}\right)$ :

$\mathbf{H}_{0}$ - There will be no established between "groups" difference of the respondents of different $\boldsymbol{E} \boldsymbol{O}$, concerning the applied items within 11 segments of the $\boldsymbol{Q}$, defined as $\left(\mathrm{C}_{1}\right.$. $\left.\mathrm{C}_{11}\right)$. 
$\mathbf{A}_{0}$ - There will be established a significant between "groups" difference of the respondents of different $\boldsymbol{E} \boldsymbol{O}$, concerning the tested items within 11 segments of the $\boldsymbol{Q}$.

When it is about gender differences within $H \boldsymbol{C}$ sub-samples (Boys/Girls), the research results will be provided only in form of relative values, in tables, within 11 scales of the $\boldsymbol{Q}$, and 37 items (study questions), with 4-levels of Likert-type scale statements modalities.

\section{Review of Literature}

Considering a small number of researches, elaborated in this field in home country, and region-wide, dealing with the estimation of the quality of life in children and youth, this study is partly based on the model, which was implemented by Kvrgić, S, (2001), and published as a monograph Quality of life of schoolchildren and youth. The next important research in this area was conducted by Samouilidou, E. (2004), and published as a monograph Stimulation of the motor development in pupils with mental retardation.

\section{Research Method}

This comparative analysis provides the evaluation of the research results, collected during the physical education (PE) classes, with upper Elementary school students in Nis (as $\mathrm{HC})$, and with the foreign country students of Greece.

Unlike the model, implemented in the above mentioned research, with two version of the $\boldsymbol{Q}$ (children and parental), in this pilot study was applied only $\boldsymbol{Q}$, concerning to the components of the QLHSW, in school children (without the consideration of parental situation, only in Introductory part, Table A).

The observed variables are items. The characteristics concerning the divided sample of HC students to the sub-samples by gender is a criterion. More items, which are connected to each other meaningfully, and make a logical order are called simply "whole" (C). All observed thematic sections make a field of examination, regarding the criterion difference, as stated in Global hypothesis as "groups" of different EO.

\subsection{Sample}

Total sample of 45 respondents, divided into two samples, according to different $\boldsymbol{E O}$ : Greek students (from Northern Aegean Region), not very balanced in terms of gender (13 male/2 female), up 10-11 to 16-17 years of age, and $\mathbf{H C}$ students of a Serbian citizenship (of Niš), good balanced in terms of gender (15 male/15 female), up 10-11 to 14-15 years of age.

\subsection{Instrument of Research}

Applied $\mathbf{Q}$ is designed to assess the Quality of Life, Health and Social Wellness. Introductory part contain seven sections, dealing with some socio demographic indicators concerning the parental situation of the respondents. The following segments of the $\mathbf{Q}$ refers to the eleven applied scales $\left(\mathrm{C}_{1} \mathrm{C}_{11}\right)$, and offered four levels of statements modalities, on Likert-type scale up 1-4 points of intensity. Names and description of certain scale are provided according to Kvrgić, S. (2001): pp. 22-24, by Source: The CHQ 
User's Manual. Landgraf, Ware, Abetz, 1996.

\subsection{Area of research}

The introductory part of the $\boldsymbol{Q}$ (Table „A') and assessed with seven parts (1-7), regarding some demographic, and social status variables of upper elementary school students, and their parents. All obtained data were analyzed only based on the absolute and relative frequencies of statements modalities, within provided items on gender, age, level of education and professional position of children (when applicable), and parents.

The main area of this research consists of eleven thematic scales, which are analyzed concerning different "groups" of EO, related to ethnic specificity, and gender differences comparison: $\mathrm{C}_{1}-$ Scale of physical functioning; $\mathrm{C}_{2}-$ Scale of social roles implementations; $\mathrm{C}_{3}-$ Scale of Global health; $\mathrm{C}_{4}-\mathrm{Scale}$ of Bodily pain; $\mathrm{C}_{5}-\mathrm{Scale}$ of Psychological impact on parents; $\mathrm{C}_{6}-\mathrm{Scale}$ of Social roles implementation; $\mathrm{C}_{7}-\mathrm{Scale}$ of Self-assessment; $\mathrm{C}_{8}-\mathrm{Scale}$ of Mental health; $\mathrm{C}_{9}-$ Scale of Behavior; $\mathrm{C}_{10}-$ Scale of Family activities and relationships; $\mathrm{C}_{11}-$ Scale of Health changes.

\subsection{Mathematical-Statistical model of data processing} a. Applied processes

Data was processed with the appropriate mathematical-statistical procedures (M-S). The analysis was conducted in three steps as follows: hypothesis testing about the similarities or differences, specifying measures of the differences, and defining characteristics.

The 1 st level are items, given in the form of a statements. At the 2nd level, item-like particles are observed in the sub-scales that cover different dimensions of QLHSW. The raw scores of each scale are transformed into standardized, with an appropriate statements modalities, which facilitates the interpretation of the results. The 3rd level represents total physical and psycho-social health. Up to this level, there are certain statistical procedures, based on the individual scale scores.

Eleven segments of $\mathbf{Q},\left(\mathrm{C}_{1} \mathrm{C}_{11}\right)$ with applied 37 items, have non-parametric properties, and they are analyzed with non-parametric methods, regarding the frequency of statements modalities. For data analysis was used multivariate procedures: Multivariate Analysis of Variance (MANOVA) and Discriminate Analysis (DISCRA). The purpose of the application of $\boldsymbol{M}-\boldsymbol{S}$ analysis is to determine the characteristics of the samples homogeneity, and the distance between them in relation to the estimated criterion characteristics, and for the reason of reliable and accurately prediction and prognosis with positive significance.

\section{b. Testing of the hypothesis}

The methods used for proving the existence of similarities or differences, between sub-samples, confirm the hypothesis or reject it, or indicate the existence of differences. When testing the hypothesis it is used critical value $\boldsymbol{p}$, which means the risk of conclusion. If $\boldsymbol{p}>\mathbf{0 . 1}$ there is no reason not to accept the initial hypothesis. For the rejection of the initial hypotheses are used two levels of significance. In the case where $0.1>p>0.05$ the alternative hypothesis is accepted with an increased risk of conclusion, when $\boldsymbol{p}<\mathbf{0 . 0 5}$ the alternative hypothesis is accepted, and points out on significant differences. 
The procedure of (MANOVA) was used to test the hypothesis $\mathrm{H}_{1}$ :

$\mathrm{H}_{1}$ - There are no significant differences between sub-samples for the given thematic unit.

$A_{1}$ - There are significant differences between sub-samples for the given thematic unit.

The procedure of (DISCRA) to test the hypothesis $\mathrm{H}_{2}$ :

$\mathrm{H}_{2}$ - There is no clearly defined border between sub-samples for the given thematic unit.

$\mathrm{A}_{2}$ - There is a clearly defined border between sub-samples for the given thematic unit.

\section{Discussion}

To avoid losing of information, finding the finest links and information's, on nonparametric values, data scaling is performed on the tables of contingency. This procedure, based on the unit frequency, for each part is given a real number, which reflects the intensity of item modalities, within certain scales of the $\boldsymbol{Q}$.

4.1 Survey of the Introductory part " $\mathrm{A}^{\prime \prime}$ of $(\mathrm{Q})$ within 7 segments (43 items) of the Student's Social Status, different "Groups" of EO, and HC Gender Comparison

In the Introductory part of $\boldsymbol{Q}$ (Table-A), are provided the basic social-status components, within the SSS (1-7) of the upper elementary school students, and some demographic data on home (SRB-2), and foreign country (GRE-1) examinees, and their parents.

\begin{tabular}{|c|c|c|c|c|}
\hline \multicolumn{5}{|c|}{ Table A. The Student's Social Status - SSS (1-7) } \\
\hline 01 & \multicolumn{4}{|c|}{ Gender } \\
\hline SAMPLES / Sub-samples & $\begin{array}{l}S R B-2 \\
(N=30)\end{array}$ & $\begin{array}{c}\text { Boys-2 } \\
(n=15)\end{array}$ & $\begin{array}{c}\text { Girls-2 } \\
(n=15)\end{array}$ & GRE-1 $(N=15)$ \\
\hline 02 & \multicolumn{4}{|c|}{ Child parenting } \\
\hline SAMPLES / Sub-samples & $\begin{array}{l}S R B-2 \\
(N=30)\end{array}$ & $\begin{array}{c}\text { Boys-2 } \\
(n=15)\end{array}$ & $\begin{array}{c}\text { Girls-2 } \\
(n=15)\end{array}$ & GRE-1 $(N=15)$ \\
\hline Both parents & $83.3 \%$ & $80 \%$ & $86.7 \%$ & $73.3 \%$ \\
\hline Mother & $16.7 \%$ & $20 \%$ & $13.7 \%$ & $20 \%$ \\
\hline Father & $(-)$ & $(-)$ & $(-)$ & $6.7 \%$ \\
\hline 03 & \multicolumn{4}{|c|}{ Age of the Children } \\
\hline SAMPLES / Sub-samples & $\begin{array}{l}S R B-2 \\
(N=30)\end{array}$ & $\begin{array}{c}\text { Boys-2 } \\
(n=15)\end{array}$ & $\begin{array}{c}\text { Girls-2 } \\
(n=15)\end{array}$ & GRE-1 $(N=15)$ \\
\hline$(10-11)$ & $6.7 \%$ & $13.3 \%$ & $(-)$ & $(-)$ \\
\hline$(12-13)$ & $66.7 \%$ & $60 \%$ & $73.3 \%$ & $13.3 \%$ \\
\hline (14-15) & $26.7 \%$ & $26.7 \%$ & $26.7 \%$ & $60 \%$ \\
\hline$(16-17)$ & $(-)$ & $(-)$ & $(-)$ & $26.7 \%$ \\
\hline 04 & \multicolumn{4}{|c|}{ Age of the Parents } \\
\hline SAMPLES/Sub-samples & $\begin{array}{l}S R B-2 \\
(N=30)\end{array}$ & $\begin{array}{c}\text { Boys-2 } \\
(n=15)\end{array}$ & $\begin{array}{c}\text { Girls-2 } \\
(n=15)\end{array}$ & GRE-1 $(N=15)$ \\
\hline Father (years) & 48.2 & 47.1 & 49.1 & 43.8 \\
\hline Mother (years) & 41 & 38.4 & 43.7 & 41.7 \\
\hline 05 & \multicolumn{4}{|c|}{ Grade level of Children } \\
\hline SAMPLES / Sub-samples & $\begin{array}{l}S R B-2 \\
(N=30)\end{array}$ & $\begin{array}{c}\text { Boys-2 } \\
(n=15)\end{array}$ & $\begin{array}{c}\text { Girls-2 } \\
(n=15)\end{array}$ & GRE-1 $(N=15)$ \\
\hline 6th Grade (10-11 years) & $70 \%$ & $73.3 \%$ & $66.7 \%$ & $(-)$ \\
\hline 7th Grade (12-13 years) & $(-)$ & $(-)$ & $(-)$ & $13.3 \%$ \\
\hline
\end{tabular}


Britain International of Humanties and Social Sciences (BIoHS) Journal

ISSN: 2685-3868(Online), 2685-1989(Print)

Vol. 2, No. 1, February 2020, Page: 127-142

\begin{tabular}{|c|c|c|c|c|}
\hline 8th Grade (14-15 years) & $30 \%$ & $26.7 \%$ & $33.3 \%$ & $40 \%$ \\
\hline 9th Grade (16-17 years) & $(-)$ & $(-)$ & $(-)$ & $46.7 \%$ \\
\hline $06 a$ & \multicolumn{4}{|c|}{ Educational Level of Parent - Father (A) } \\
\hline SAMPLES/Sub-samples & $S R B-2(N=30)$ & Boys-2 $(n=15)$ & $\begin{array}{c}\text { Girls-2 } \\
(n=15)\end{array}$ & $\underset{)}{G R E-1(N=15}$ \\
\hline Completed primary School & $7.2 \%$ & $13.3 \%$ & $(-)$ & $(-)$ \\
\hline Incomplete-Secondary/Vocational & $3.6 \%$ & $6.7 \%$ & $(-)$ & $6.67 \%$ \\
\hline Secondary-School Diploma & $28.6 \%$ & $26.7 \%$ & $28.6 \%$ & $60 \%$ \\
\hline College & $28.6 \%$ & $30 \%$ & $35.7 \%$ & $(-)$ \\
\hline High-School Education & $32.1 \%$ & $33.3 \%$ & $28.6 \%$ & $33.3 \%$ \\
\hline $06 b$ & \multicolumn{4}{|c|}{ Educational Level of Parent -Mother (B) } \\
\hline SAMPLES/Sub-samples & $\begin{array}{l}S R B-2 \\
(N=30)\end{array}$ & $\begin{array}{c}\text { Boys-2 } \\
(n=15)\end{array}$ & $\begin{array}{c}\text { Girls-2 } \\
(n=15)\end{array}$ & GRE-1 $(N=15)$ \\
\hline Completed primary School & $10.7 \%$ & $13.3 \%$ & $6.7 \%$ & $(-)$ \\
\hline Incomplete-Secondary/Vocational & $(-)$ & $(-)$ & $(-)$ & $(-)$ \\
\hline Secondary-School Diploma & $21.4 \%$ & $30 \%$ & $20 \%$ & $(-)$ \\
\hline College & $32.1 \%$ & $13.3 \%$ & $46.7 \%$ & $(-)$ \\
\hline High-School Education & $35.7 \%$ & $40 \%$ & $46.7 \%$ & $(-)$ \\
\hline $07 a$ & \multicolumn{4}{|c|}{ Occupation of Parent - Father (A) } \\
\hline SAMPLES/Sub-samples & $\begin{array}{l}S R B-2 \\
(N=30)\end{array}$ & $\begin{array}{c}\text { Boys-2 } \\
(n=15)\end{array}$ & $\begin{array}{c}\text { Girls-2 } \\
(n=15)\end{array}$ & GRE-1 $(N=15)$ \\
\hline Unemployed & $7.1 \%$ & $7.1 \%$ & $7.1 \%$ & $6.67 \%$ \\
\hline Farmer & $(-)$ & $(-)$ & $(-)$ & $(-)$ \\
\hline Wage worker/laborer & $3.6 \%$ & $7.1 \%$ & $(-)$ & $(-)$ \\
\hline Industrial Worker, Craftsman & $(-)$ & $6.1 \%$ & $(-)$ & $(-)$ \\
\hline Civil servant/Entrepreneur & $50 \%$ & $50 \%$ & $50 \%$ & $60 \%$ \\
\hline Manager/Businessman & $17.8 \%$ & $21.4 \%$ & $14.3 \%$ & $13.3 \%$ \\
\hline Other (specify profession) & $21.4 \%$ & $14.3 \%$ & 28.6 & $20 \%$ \\
\hline $07 b$ & \multicolumn{4}{|c|}{ Occupation of Parent - Mother (B) } \\
\hline SAMPLES / Sub-samples & $\begin{array}{l}S R B-2 \\
(N=30)\end{array}$ & $\begin{array}{c}\text { Boys-2 } \\
(n=15)\end{array}$ & $\begin{array}{c}\text { Girls-2 } \\
(n=15)\end{array}$ & GRE-1 $(N=15)$ \\
\hline Unemployed & $15.4 \%$ & $6.7 \%$ & $20 \%$ & $(-)$ \\
\hline Housewife & $11.5 \%$ & $14.3 \%$ & $6.7 \%$ & $(-)$ \\
\hline Wage worker/Laborer & $3.85 \%$ & $(-)$ & $6.7 \%$ & $(-)$ \\
\hline Industrial Worker/Craftsman & $3.85 \%$ & $6.7 \%$ & $(-)$ & $(-)$ \\
\hline Civil servant / Entrepreneur & $38.5 \%$ & $29 \%$ & $40 \%$ & $(-)$ \\
\hline Manager / Businessman & $3.3 \%$ & $6.7 \%$ & $(-)$ & $(-)$ \\
\hline Other (specify profession) & $20.7 \%$ & $21.4 \%$ & $20 \%$ & $(-)$ \\
\hline
\end{tabular}

4.2. Survey on the Quality of Life, Health and Social Wellness (Q) within eleven segments and 37 items, regarding the different "Groups" of EO, and HC sub-samples Gender specificity comparison

$\mathbf{C}_{1}$ - The Scale Of The Physical Functioning, measures the presence and extent of physical limitations caused by health problems, and contains three important dimensions: selfcare, mobility, and activities that require more effort. The presence and degree of limitation are 
estimated on 4-points scale, up "very limited" to "no limit". A low score indicates that health problems significantly limit the children in performing all physical activities (PA), whereas a high score means that a children perform (PA), without restrictions.

\begin{tabular}{|l|l|l|l|l|}
\hline \multicolumn{5}{|c|}{ Table 1. The Scale of Physical Functioning - SPF (8-10) } \\
\hline \multicolumn{5}{|c|}{ H-8) Is independent students care about them limited due to health conditions? } \\
\hline SAMPLES / Sub-samples & SRB-2 (N=30) & Boys-2 (n=15) & Girls-2 (n=15) & GRE-1 (N=15) \\
\hline no limit & $\mathbf{7 2 . 3 \% ( 4 ) *}$ & $\mathbf{6 4} \%$ & $80 \%$ & $26.7 \%$ \\
\hline partially restricted & $24.3 \%$ & $29 \%$ & $20 \%$ & $33.3 \%$ \\
\hline mostly limited & $3.4 \%$ & $7.1 \%$ & $(-)$ & $40 \%(2)$ \\
\hline \multicolumn{5}{|c|}{ (I-9) How many daily activities are limited because of student's physical health? } \\
\hline SAMPLES / Sub-samples & SRB-2 (N=30) & Boys-2 (n=15) & Girls-2 (n=15) & GRE-1 (N=15) \\
\hline no limit & $\mathbf{8 3 \%}(\mathbf{4})^{*}$ & $\mathbf{8 0} \%$ & $80 \%$ & $33.3 \%$ \\
\hline somewhat limited & $6.9 \%$ & $(-)$ & $13.3 \%$ & $20 \%$ \\
\hline occasionally limited & $10 \%$ & $20 \%$ & $6.7 \%$ & $46.7 \%(2) *$ \\
\hline (J-10) How much health status influenced the performance of PA that require more effort? \\
\hline SAMPLES / Sub-samples & SRB-2 (N=30) & Boys-2 (n=15) & Girls-2 (n=15) & GRE-1 (N=15) \\
\hline no restrictions & $75.8 \%(4) *$ & $78.6 \%$ & $73.3 \%$ & $40 \%(4)$ \\
\hline partially restricts & $6.9 \%$ & $(-)$ & $13.3 \%$ & $26.7 \%(3)^{*}$ \\
\hline occasionally restricts & $10.3 \%$ & $14.3 \%$ & $6.7 \%$ & $33.3 \%(2)^{*}$ \\
\hline completely restrict & $6.9 \%$ & $7.1 \%$ & $6.7 \%$ & $(-)$ \\
\hline
\end{tabular}

Note (stated for all Tables (1-11): In parenthesis are marked statements modalities up (1)* to $(4)^{*}$, within some items, which contributed (ctrb.\%) to the statistically significant between "groups" differences.

Scale of the Physical Functioning - SPF (8-10). Based on comparative analysis of results, provided by $\mathrm{HC}$ sub-samples (Boys-2; Girls-2), there were no estimated significant gender differences, while the majority respondents opted for the statement "no limit" or "no restrictions" on the provided items within SPF (8-10) in Table 1.

Conducted MANOVA $(\mathrm{F}=6.74, \mathrm{p}=0.001)$; and DISCRA $(\mathrm{F}=6.57, \mathrm{p}=.001)$ analysis indicates that there is a significant between «groups» difference, considering students of different EO. The established coefficients of discrimination (c.dsc) are in following items: SPF8 (.184), SFF10 (.075), SFF9 (.005), on the level of significance $(0.000,0.002,0.002$, respectively). Homogeneity (Hom. \%): (GRE-1): 10/15 (66.7\%); (SRB-2): 25/30 (83.3\%), Contribution (Ctrb. \%): H-8 (69.7); J-10 (28.4); I-9 (1.9).

$\mathrm{C}_{2}-$ Scale Of The Social Roles Implementation. Accomplishing, and the realization of social role, previously mainly estimated on absences from the school, and now is considered being of great importance as for the ability to socialize, and get along with others. Accordingly, these 4-point scales assesses to what extent physical health interfere with children everyday school activities and social contact with their friends. The low score point out on high degree of restrictions, while high score means that there is no restrictions.

Table 2. The Scale of Social Role Implementation -SSRI - (11-12)

(K-11) The extent to which physical health interfere with everyday school activities?

\begin{tabular}{l|l|l|l|l} 
SAMPLES/Sub-samples & SRB-2 $(N=30)$ & Boys-2 $(n=15)$ & Girls-2 $(n=15)$ & GRE-1 $(N=15)$
\end{tabular}


Britain International of Humanties and Social Sciences (BIoHS) Journal

ISSN: 2685-3868(Online), 2685-1989(Print)

Vol. 2, No. 1, February 2020, Page: 127-142

\begin{tabular}{|c|c|c|c|c|}
\hline no restrictions & $62.1 \%(4)^{*}$ & $69.2 \%$ & $60 \%$ & $33.3 \%$ \\
\hline partially restricted & $13.7 \%$ & $15.4 \%$ & $13.3 \%$ & $40 \%(3) *$ \\
\hline occasionally restricted & $20.7 \%$ & $15.4 \%$ & $26.7 \%$ & $26.7 \%$ \\
\hline very restricted & $3.4 \%$ & $(-)$ & $(-)$ & $(-)$ \\
\hline \multicolumn{5}{|c|}{ (L-12) The extent to which students physical health disrupts daily social activities } \\
\hline SAMPLES/Sub-samples & $S R B-2(N=30)$ & Boys-2 $(n=15)$ & Girls-2 $(n=15)$ & GRE-1 $(N=15)$ \\
\hline no restrictions & $76.9 \%(4)^{*}$ & $76.9 \%$ & $66.7 \%$ & $26.7 \%(4)^{*}$ \\
\hline partially restricted & $3.8 \%$ & $(-)$ & $13.3 \%$ & $46.7 \%(3)^{*}$ \\
\hline occasionally restricted & $11.5 \%$ & $15.4 \%$ & $6.7 \%$ & $26.7 \%(2)^{*}$ \\
\hline completely restricted & $7.7 \%$ & $7.7 \%$ & $6.7 \%$ & $(-)$ \\
\hline
\end{tabular}

Scale of the Social Role Implementation (SRI), depending on physical health. No significant gender differences, between HC-students (Boys-2/Girls-2), were estimated. The majority of children evaluate these items as with "no restrictions". Conducted MANOVA $(\mathrm{F}=10.32, \mathrm{p}=.000)$, and DISCRA $(\mathrm{F}=11.58, \mathrm{p}=.000)$ analysis indicate that there are a significant between "groups» differences, considering students of different EO. The established (c.dsc) are in following items, on the level of significance: SSR12 (0.451), SSR11 (.046), SSR13 (0.003). Hom. (\%): GRE-1: 11/15 (73.3\%); SRB-2: 24/30 (80\%); Ctrb. (\%): L-12 (99.4), K-11 (0.66).

$\mathrm{C}_{3}-$ The Scale Of The Global Health. In this part of the questionnaire respondents subjectively evaluate past, present and future health status, as well as susceptibility to diseases, by expressing its agreement with the statements on the 4-point scale. A low score means that the children's health is assessed as poor (very bad), with a worsening trend, whereas a high score comes to evaluating health as excellent and the belief that it will remain so.

\begin{tabular}{|c|c|c|c|c|}
\hline \multicolumn{5}{|c|}{ Table 3. The Scale of the Global Health - D-SGH (13-15) } \\
\hline \multicolumn{5}{|c|}{ (M-13) What is a subjective assessment of a students' health in the past year? } \\
\hline SAMPLES/Sub-samples & $S R B-2(N=30)$ & Boys-2 ( $n=15)$ & Girls-2 (n=15) & GRE-1 $(N=15)$ \\
\hline excellent & $55.6 \%(4) *$ & $83.3 \%$ & $33.3 \%$ & $33.3 \%$ \\
\hline very good & $44.4 \%$ & $16.7 \%$ & $66.7 \%$ & $53.3 \%$ \\
\hline occasionally poor & $(-)$ & $(-)$ & $(-)$ & $13.3 \%(2)^{*}$ \\
\hline \multicolumn{5}{|c|}{$(\mathrm{N}-14)$ What is a subjective assessment of the current health status of students? } \\
\hline SAMPLES/Sub-samples & $S R B-2(N=30)$ & Boys-2 (n=15) & Girls-2 (n=15) & GRE-1 $(N=15)$ \\
\hline excellent & $71 \%(4)^{*}$ & $85 \%$ & $60 \%$ & $33.3 \%$ \\
\hline tendency to improvement & $21.4 \%$ & $7.7 \%$ & $33.3 \%$ & $33.3 \%$ \\
\hline subject to disease & $7.1 \%$ & $7.7 \%$ & $6.7 \%$ & $33.3 \%(2)^{*}$ \\
\hline \multicolumn{5}{|c|}{ (O-15) What is a subjective assessment of the future health of students? } \\
\hline SAMPLES/Sub-samples & $S R B-2(N=30)$ & Boys-2 (n=15) & Girls-2 (n=15) & GRE-1 $(N=15)$ \\
\hline shall be great & $65.4 \%(4)^{*}$ & $75 \%$ & $57.1 \%$ & $33.3 \%$ \\
\hline very good & $26.9 \%$ & $16.7 \%$ & $33.3 \%$ & $20 \%$ \\
\hline tendency to improvement & $3.8 \%$ & $8.3 \%$ & $(-)$ & $46.7 \%(2)^{*}$ \\
\hline bad, with deteriorating & $3.8 \%$ & $(-)$ & $6.7 \%$ & $(-)$ \\
\hline
\end{tabular}

Scale of the Global Health (SGH). The majority of respondents opted for the statements modalities as excellent and very good, with the prevalence of the percentage in boys. Provided statements do not established significant gender difference between HC sub- 
samples (Boys-2/Girls-2). Conducted MANOVA ( $\mathrm{F}=3.63, \mathrm{p}=.021)$, and DISCRA ( $\mathrm{F}=3.545$, $\mathrm{p}=.023)$ analysis indicates that there is a significant between «groups» difference, considering school students of different EO. The established (c.dsc) are in following items: SGH15 (0.097), SGH13 (0.012), SGH14 (0.009), on the level of significance: $(0.004,0.021,0.028$, respectively). Hom.\%: GRE-1: 7/15 (46.7\%); SRB-2: 25/30 (83.3\%). Ctrb.\%: O-15 (82.2\%), M-13 (10.2\%), N-14 (7.6\%).

$\mathbf{C}_{4}$-The Scale Of The Bodily Pain, designed to measure the intensity and frequency of pain, as one of the indicators of physical health. The pain or discomfort is assessed through responses ranging up "no pain" to "presence of a strong pain" (within a period of the last 4 weeks, from the day of survey assessment). A low score means that the child fills extremely strong, frequent and restrictive pain, whereas a high score speaks of the absence of pain.

\begin{tabular}{|c|c|c|c|c|}
\hline \multicolumn{5}{|c|}{ Table 4. The Scale of Bodily Pain -SBP (16-17) } \\
\hline \multicolumn{5}{|c|}{ (P-16) What is a subjective assessment of pain as indicator of student's health status? } \\
\hline SAMPLES/Sub-samples & $S R B-2(N=30)$ & Boys-2 ( $n=15)$ & Girls-2 (n=15) & GRE-1 $(N=15)$ \\
\hline no pain & $68 \%(4)^{*}$ & $77 \%$ & $60 \%$ & $20 \%$ \\
\hline anxiety & $7.1 \%$ & $7.7 \%$ & $6.7 \%$ & $40 \%(3) *$ \\
\hline some pain & $21.4 \%$ & $15.3 \%$ & $26.7 \%$ & $26.7 \%$ \\
\hline presence of a strong pain & $3.6 \%$ & $(-)$ & $6.7 \%$ & $13.3 \%$ \\
\hline \multicolumn{5}{|c|}{ (Q-17) Frequency of the subjective fill of pain as one of the indicators of students health status? } \\
\hline SAMPLES/Sub-samples & $S R B-2(N=30)$ & Boys-2 ( $n=15)$ & Girls-2 (n=15) & GRE-1 $(N=15)$ \\
\hline no pain & $57 \%(4) *$ & $77 \%$ & $46.7 \%$ & $20 \%$ \\
\hline occasional discomfort & $30 \%$ & $23 \%$ & $40 \%$ & $73.3 \%(3) *$ \\
\hline almost every day pain & $13 \%$ & $(-)$ & $13.3 \%$ & $6.7 \%$ \\
\hline
\end{tabular}

The Scale of Bodily Pain (SBP). Provided statements do not established significant gender difference between HC sub-samples (Boys-2/Girls-2), while the majority of respondents opted for the statement "no pain", with some prevalence of higher percentage in boys. Conducted MANOVA $(\mathrm{F}=6.19, \mathrm{p}=.003)$, and DISCRA $(\mathrm{F}=6.65, \mathrm{p}=.003)$ analysis indicates a significant between «groups» difference, considering school students of different EO. The established (c.dsc) are in following items: SBP16 (0.137), SBP17 (0.035), on the level of significance: (0.001, 0.009, respectively). Hom. (\%): GRE-1: 12/15 (80\%); SRB-2: 22/30 (73.3\%). Ctrb. (\%): P-16 (79.65), Q-17 (20.35).

$\mathrm{C}_{5}$ - The Scale Of The Emotional Impact On The Parents. The Scale is 4-point, and the responses are in range from "very limited" to "not limit". A low score point out on high degree of limitation in the time available for personal needs, due to child physical, and/or psycho-social health. A high score means that a parent do not experiencing such a limitations.

Table 5. The Scale of the Emotional Impact on Parents -EIP (18-19)
\begin{tabular}{|l|l|l|l|l|}
\hline $\begin{array}{l}\text { (R-18) How do students assesses parent's limited time for a personal need, because of child physical } \\
\text { or psycho-social health? }\end{array}$ \\
\hline SAMPLES/Sub-samples & SRB-2 (N=30) & Boys-2 (n=15) & Girls-2 (n=15) & GRE-1 (N=15) \\
\hline very limited & $11.1 \%$ & $7.7 \%$ & $14.3 \%$ & $13.3 \%$ \\
\hline occasionally limited & $14.8 \%$ & $7.7 \%$ & $14.3 \%$ & $53.3 \%(2)^{*}$ \\
\hline partially limited & $7.4 \%$ & $(-)$ & $14.3 \%$ & $33.3 \%(3)^{*}$ \\
\hline
\end{tabular}




\begin{tabular}{|c|c|c|c|c|}
\hline no limit & $66.7 \%(4)^{*}$ & $77 \%$ & $57.1 \%$ & $(-)$ \\
\hline \multicolumn{5}{|c|}{$\begin{array}{l}\text { (S-19) How do students assesses parents suffering and worries because of their physical } \\
\text { or psycho-social health? }\end{array}$} \\
\hline SAMPLES/Sub-samples & SRB-2 $(N=30)$ & Boys-2 ( $n=15)$ & Girls-2 (n=15) & GRE-1 $(N=15)$ \\
\hline no worries & $24 \%(4)^{*}$ & $30.8 \%$ & $16.7 \%$ & $(-)$ \\
\hline mild concern & $52 \% *$ & $46 \%$ & $58.3 \%$ & $26.7 \%$ \\
\hline considerable care & $20 \%$ & $15 \%$ & $23.1 \%$ & $53.3 \%(2) *$ \\
\hline high emotional concern & $4 \%$ & $7.7 \%$ & $(-)$ & $20 \%$ \\
\hline
\end{tabular}

Scale of the Emotional Impact on Parents (SEIP). The surveys conducted in the late 80 s of the 20th century by foreign researches, indicate a direct correlation between the estimated child health, and the degree to which the parent feels physically and emotionally affected. This scale has the time impact, and emotional impact. Provided statements, do not established significant gender difference between HC sub-samples (Boys-2/Girls-2), but there were some numerical differences. Conducted MANOVA $(F=15.004, p=.000)$, and DISCRA ( $\mathrm{F}=17.68, \mathrm{p}=.000)$ analysis indicates that there is a significant between "groups» difference, considering school students of different EO. The established (c.dsc) are in following items: SEIP18 (0.550), SEIP19 0.227), on the level of significance: $(0.000,0.001$, respectively). Hom.\%: GRE-1: 14/15 (93.3\%); SRB-2: 21/30 (70\%). Ctrb. (\%): R-18 (70.8), S-19 (29.2).

$\mathrm{C}_{6}-$ The Scale Of The Emotional State And Bahavior. For the realization of the social role, which includes daily activities, such are school activities, and social activities with friends, in addition to the physical health of the great importance are the emotional state and behavior. The Scales, which measures this effect have been constructed as a 4-points and can be separated, but also can be a unique-form scale that talks about the combined impact of emotions and behaviors for the realization of social role. A low score means that the child is, because of his behavior or emotional problems, substantially limited in performing school or other daily activities with friends, while a high score means that there are no restrictions.

\begin{tabular}{|c|c|c|c|c|}
\hline \multicolumn{5}{|c|}{ Table 6. The Scale of the Emotional State and Behavior-SESB (20-23) } \\
\hline \multicolumn{5}{|c|}{ (T-20) How are, by the personal student judgment limited schooling and obligations because of heal } \\
\hline SAMPLES/Sub-samples & SRB-2 $(N=30)$ & Boys-2 ( $n=15)$ & Girls-2 (n=15) & GRE-1 $(N=15)$ \\
\hline no restrictions & $61.5 \%(4)^{*}$ & $61.5 \%$ & $61.5 \%$ & $(-)$ \\
\hline partially restricted & $30.8 \%$ & $30 \%$ & $30.8 \%$ & $66.7 \%(3)^{*}$ \\
\hline occasionally restricted & $7.7 \%$ & $7.7 \%$ & $7.7 \%$ & $33.3 \%$ \\
\hline \multicolumn{5}{|c|}{ (U-21) On the personal judgment, haw was limited activities with students because of med. conditio } \\
\hline SAMPLES/Sub-samples & $S R B-2(N=30)$ & Boys-2 (n=15) & Girls-2 (n=15) & GRE-1 $(N=15)$ \\
\hline no restrictions & $66.7 \%(4)^{*}$ & $64.3 \%$ & $69.2 \%$ & $(-)$ \\
\hline somewhat limited & $7.4 \%$ & $14.3 \%$ & $(-)$ & $66.7 \%(3)^{*}$ \\
\hline occasionally limited & $22.2 \%$ & $21.4 \%$ & $23.1 \%$ & $33.3 \%$ \\
\hline completely restricted & $3.7 \%$ & $(-)$ & $7.7 \%$ & $(-)$ \\
\hline \multicolumn{5}{|c|}{ (V-22) What is the emotional state of students in relation to restrictions on health grounds? } \\
\hline SAMPLES/Sub-samples & $S R B-2(N=30)$ & Boys-2 ( $n=15)$ & Girls-2 (n=15) & GRE-1 (N=15) \\
\hline great mood & $55.6 \%(4)^{*}$ & $57.1 \%$ & $53.8 \%$ & $(-)$ \\
\hline good mood & $29.6 \%$ & $35.7 \%$ & $23.1 \%$ & $40 \%$ \\
\hline
\end{tabular}


Britain International of Humanties and Social Sciences (BIoHS) Journal

ISSN: 2685-3868(Online), 2685-1989(Print)

Vol. 2, No. 1, February 2020, Page: 127-142

\begin{tabular}{|l|l|l|l|l|}
\hline changing mood & $11.1 \%$ & $7.1 \%$ & $15.4 \%$ & $60 \%(2)^{*}$ \\
\hline depression & $3.7 \%$ & $(-)$ & $7.7 \%$ & $(-)$ \\
\hline (W-23) What is the behavior of students in relation to the restrictions on the health grounds? \\
\hline SAMPLES/Sub-samples & SRB-2 (N=30) & Boys-2 (n=15) & Girls-2 (n=15) & GRE-1 (N=15) \\
\hline active attitude & $\mathbf{6 4 . 3 \% ( 4 ) *}$ & $71.4 \%$ & $61.5 \%$ & $(-)$ \\
\hline benevolent & $17.8 \%$ & $7.1 \%$ & $30.8 \%$ & $60 \%(3)^{*}$ \\
\hline occasional outbursts & $10.7 \%$ & $21.4 \%$ & $(-)$ & $40 \%(2)^{*}$ \\
\hline hostile & $7.2 \%$ & $(-)$ & $7.7 \%$ & $(-)$ \\
\hline
\end{tabular}

Scale of the Emotional State and Behavior (SESB), presents relative values within items, and provides statements, which do not pointed on significant gender differences between HC sub-samples (Boys-2; Girls-2), while in majority of statements, respondents opted for the highest intensity, which means that there are no limitations, when considering the combined impact of emotions and behaviors for the realization of social role, with some prevalence of higher percentage of statements in boys, except in item U21, with some higher percentage of statements in girls. Conducted MANOVA ( $\mathrm{F}=13.995, \mathrm{p}=.000)$, and DISCRA $(\mathrm{F}=13.995, \mathrm{p}=.000)$ analysis indicates that there is a significant between "groups» difference, considering school students of different EO. The established (c.dsc) are in following items: SESB21 (0.572), SESB22 (0.150), SESB23 (0.017), SESB20 (0.016), on the level of significance: $(0.000,0.000,0.000,0.000$, respectively). Hom. (\%): GRE-1: 15/15 (100\%); SRB-2: 25/30 (83.3\%). Ctrb. (\%): U-21 (75.8), V-22 (19.9), W-23 (2.25), T-20 (2.1).

C7 - The Self Evaluation Scale. The self-assessment is a multi-dimensional phenomenon that occurs during a pre-adolescence period, and shape and redefines during the life-time, and includes three essential components: social security (confidence), academic skills, and self-esteem. The Scale, used in this survey includes the following dimensions: satisfaction of the school achievement, and physical abilities, satisfaction with appearance, as well the ability of agreement with others, and with family members, and overall satisfaction with life. Answers vary up "very satisfied" to "very dissatisfied", whereas the low score points out that on very dissatisfied child, and the high score points out on very satisfied child with their abilities, appearance, family relationships and overall life satisfaction.

\begin{tabular}{|c|c|c|c|c|}
\hline \multicolumn{5}{|c|}{ Table 7. The Self Evaluation Scale - SES (24-28) } \\
\hline \multicolumn{5}{|c|}{ (X-24) How satisfied are students with their academic achievement? } \\
\hline SAMPLES/Sub-samples & SRB-2 $(N=30)$ & Boys-2 ( $n=15)$ & Girls-2 (n=15) & GRE-1 $(N=15)$ \\
\hline very satisfied & $63 \%(4)^{*}$ & $71.4 \%$ & $38.5 \%$ & $6.7 \%$ \\
\hline mostly satisfied & $30 \%$ & $21.4 \%$ & $53.8 \%$ & $86.7 \%(3)^{*}$ \\
\hline mostly dissatisfied & $3.5 \%$ & $7.1 \%$ & $7.7 \%$ & $6.7 \%$ \\
\hline very dissatisfied & $3.5 \%$ & $(-)$ & $(-)$ & $(-)$ \\
\hline \multicolumn{5}{|c|}{ (Y-25) How the students' are satisfied with their physical abilities? } \\
\hline SAMPLES/Sub-samples & SRB-2 $(N=30)$ & Boys-2 (n=15) & Girls-2 (n=15) & GRE-1 (N=15) \\
\hline very satisfied & $46.4 \%(4)^{*}$ & $57.1 \%$ & $42.8 \%$ & $6.7 \%$ \\
\hline mostly satisfied & $46.4 \%$ & $42.9 \%$ & $50 \%$ & $93.3 \%(3)^{*}$ \\
\hline mostly dissatisfied & $7.2 \%$ & $(-)$ & $7.2 \%$ & $(-)$ \\
\hline \multicolumn{5}{|c|}{ (Z-26) How are the students satisfied with their appearance? } \\
\hline SAMPLES/Sub-samples & $S R B-2(N=30)$ & Boys-2 ( $n=15)$ & Girls-2 (n=15) & GRE-1 $(N=15)$ \\
\hline
\end{tabular}


Britain International of Humanties and Social Sciences (BIoHS) Journal ISSN: 2685-3868(Online), 2685-1989(Print)

Vol. 2, No. 1, February 2020, Page: 127-142

\begin{tabular}{|c|c|c|c|c|}
\hline very satisfied & $62.9 \%(4)^{*}$ & $85.7 \%$ & $38.5 \%$ & $(-)$ \\
\hline mostly satisfied & $22.2 \%$ & $14.3 \%$ & $30.8 \%$ & $6.7 \%$ \\
\hline mostly dissatisfied & $7.4 \%$ & $(-)$ & $15.4 \%$ & $86.7 \%(3)^{*}$ \\
\hline very dissatisfied & $7.4 \%$ & $(-)$ & $15.4 \%$ & $6.7 \%$ \\
\hline \multicolumn{5}{|c|}{ (AA-27) Student's personal assessment relative to the ability of conformity with friends and family membe } \\
\hline SAMPLES/Sub-samples & $S R B-2(N=30)$ & Boys-2 (n=15) & Girls-2 (n=15) & GRE-1 $(N=15)$ \\
\hline very satisfied & $59 \%(4)^{*}$ & $57.1 \%$ & $61.5 \%$ & $6.7 \%$ \\
\hline mostly satisfied & $33 \%$ & $35.8 \%$ & $30.8 \%$ & $86.7 \%(3)^{*}$ \\
\hline mostly dissatisfied & $8 \%$ & $7.1 \%$ & $7.7 \%$ & $6.7 \%$ \\
\hline \multicolumn{5}{|c|}{$(A B-28)$ How are the students satisfied with overall life? } \\
\hline SAMPLES/Sub-samples & $S R B-2(N=30)$ & Boys-2 (n=15) & Girls-2 (n=15) & GRE-1 $(N=15)$ \\
\hline very satisfied & $74 \%(4)^{*}$ & $78.6 \%$ & $69 \%$ & $6.7 \%$ \\
\hline mostly satisfied & $14.8 \%$ & $21.4 \%$ & $8 \%$ & $80 \%(3) *$ \\
\hline mostly dissatisfied & $7.5 \%$ & $(-)$ & $15 \%$ & $13.3 \%$ \\
\hline very dissatisfied & $3.7 \%$ & $(-)$ & $8 \%$ & $(-)$ \\
\hline
\end{tabular}

Self Evaluation Scale (SES), presents relative values within items. Provided statements point out on some numerical gender difference between HC students (Boys/Girls), while in all items boys opted for the highest score (very satisfied). Girls students does not provide such confidence in social security, academic skills and self-esteem, except when it is about the ability of conformity with others. Conducted MANOVA ( $F=8.296$, $\mathrm{p}=.000)$, and DISCRA $(\mathrm{F}=7.98, \mathrm{p}=.000)$ analysis indicates that there is a significant between "groups» difference, considering school students of different EO. The established (c.dsc) are in following items: SES28 (0.192), SES24 (0.127), SES27 (0.032), SES26 (0.025), SES25 $(0.000)$, on the level of significance: $(0.000,0.000,0.000,0.000,0.007$, respectively). Hom. (\%): GRE-1: 14/15 (93.3\%); SRB-2: 25/30 (83.3\%). Ctrb. (\%): AB-28 (51.1), X-24 (33.8), AA-27 (8.5), Z-26 (6.65), Y-25 (.000).

I- $\mathrm{C}_{8}-$ The Scale of the Mental Health. Measures the frequency of positive and negative states. To analyze the frequency of answers were used a 4-point scale of intensity, on which answers vary from "all the time/continuous" to "never". The low score of mental health talk about feelings of anxiety and depression that are present continuously, while a high score means that the child is calm and happy.

\begin{tabular}{|l|l|l|l|l|}
\hline \multicolumn{5}{|c|}{ Table 8. The Mental Health Scale - I-MHS (29-30) } \\
\hline \multicolumn{5}{|c|}{ (AC-29) How often are students worried because of their mental health condition? } \\
\hline SAMPLES/Sub-samples & SRB-2 $(\mathbf{N = 3 0 )}$ & Boys-2 $(\mathbf{n = 1 5 )}$ & Girls-2 (n=15) & GRE-1 (N=15) \\
\hline Never & $\mathbf{6 7 . 8 \% ( 4 ) *}$ & $\mathbf{6 1 . 5 \%}$ & $73.3 \%$ & $6.7 \%$ \\
\hline Sometimes & $28.6 \%$ & $30.7 \%$ & $26.7 \%$ & $73.3 \%(3)^{*}$ \\
\hline Almost always & $(-)$ & $(-)$ & $(-)$ & $26.7 \%(2)^{*}$ \\
\hline All the time & $3.6 \%$ & $7.7 \%$ & $(-)$ & $(-)$ \\
\hline \multicolumn{5}{|c|}{ (AD-30) How often are students happy with their physical and medical conditions? } \\
\hline SAMPLES/Sub-samples & SRB-2 (N=30) & Boys-2 (n=15) & Girls-2 (n=15) & GRE-1 (N=15) \\
\hline Never & $13 \%$ & $15.4 \%$ & $13.3 \%$ & $6.7 \%$ \\
\hline Sometimes & $17.8 \%$ & $15.4 \%$ & $20.1 \%$ & $60 \%(2)^{*}$ \\
\hline
\end{tabular}


Britain International of Humanties and Social Sciences (BIoHS) Journal

ISSN: 2685-3868(Online), 2685-1989(Print)

Vol. 2, No. 1, February 2020, Page: 127-142

\begin{tabular}{|l|l|l|l|l|}
\hline Almost always & $25 \%$ & $15.4 \%$ & $33.3 \%$ & $33.3 \%$ \\
\hline All the time & $\mathbf{4 4 . 2 \% ( \mathbf { 4 } ) ^ { * }}$ & $53.8 \%$ & $33.3 \%$ & $(-)$ \\
\hline
\end{tabular}

Scale of the Mental Health (SMH). Provided statements points out on some numerical gender difference between HC school students (Boys-2; Girls-2). Girls examinees are more confident when talk about feelings, while boys respondents score higher when it is about happiness with their physical and medical conditions. Conducted MANOVA ( $F=16.001$, $\mathrm{p}=.000)$, and DISCRA $(\mathrm{F}=19.048, \mathrm{p}=.000)$ analysis indicates on a significant between «groups» differences, considering school students of different EO. The established (c.dsc) are in following items: SHM29 (0.674), SHM30 (0.149), on the level of significance $(0.000$, 0.003, respectively). Hom. (\%): GRE-1: 14/15 (93.3\%); SRB-2: 25/30 (83.3\%). Ctrb. (\%): AC-29 (81.9), AD-30 (18.1).

$\mathbf{C}_{9}-$ The Scale Of Behaviour. Frequency of problems related to behavior are assessed on a 4-point scale of intensity, whose responses ranged up-to "always-very often-sometimesnever". The scale includes four dimensions of behavior: aggression, delinquency, hyperactivity (impulsivity), and social rejection. A low score indicates a potentially aggressive, immature and delinquent behavior, while a high score means that the child never manifest such behavior.

\begin{tabular}{|c|c|c|c|c|}
\hline \multicolumn{5}{|c|}{ Table 9. The Scale of Behavior -SBH (31-33) } \\
\hline$(A E-31)$ & \multicolumn{4}{|c|}{ How often do students exhibit aggressive behavior? } \\
\hline SAMPLES/Sub-samples & SRB-2 $(N=30)$ & Boys-2 $(n=15)$ & Girls-2 (n=15) & GRE-1 $(N=15)$ \\
\hline Never & $44.4 \%(4)^{*}$ & $58.3 \%$ & $33.3 \%$ & $6.7 \%$ \\
\hline Sometimes & $44.4 \%$ & $33.3 \%$ & $53.3 \%$ & $80 \%(3) *$ \\
\hline Very often & $11.2 \%$ & $8.3 \%$ & $13.3 \%$ & $13.3 \%$ \\
\hline$($ AF-32) & \multicolumn{4}{|c|}{ How often is student sanctioned for delinquent behavior? } \\
\hline SAMPLES/Sub-samples & $S R B-2(N=30)$ & Boys-2 (n=15) & Girls-2 (n=15) & GRE-1 $(N=15)$ \\
\hline Never & $(70.4 \%)^{*}$ & $76.9 \%$ & $60 \%$ & $6.7 \%$ \\
\hline Sometimes & $25.9 \%$ & $23.1 \%$ & $26.7 \%$ & $60 \%(3) *$ \\
\hline Very often & $(-)$ & $(-)$ & $(-)$ & $33.3 \%(2)^{*}$ \\
\hline Always & $3.7 \%$ & $(-)$ & $6.7 \%$ & $(-)$ \\
\hline$(A G-33)$ & \multicolumn{4}{|c|}{ How often do students exhibit hyperactivity/impulsivity? } \\
\hline SAMPLES/Sub-samples & $S R B-2(N=30)$ & Boys-2 ( $n=15)$ & Girls-2 (n=15) & GRE-1 $(N=15)$ \\
\hline Never & $38.5 \%(4)^{*}$ & $38.5 \%$ & $33.3 \%$ & $6.7 \%$ \\
\hline Sometimes & $26.9 \%$ & $23 \%$ & $26.7 \%$ & $66.7 \%(3)^{*}$ \\
\hline Very often & $34.6 \%$ & $38.5 \%$ & $26.7 \%$ & $26.7 \%$ \\
\hline
\end{tabular}

Scale of Behavior (SBH) presents relative values within items. The provided statements point out on some numerical gender difference, between HC sub-samples (Boys2; Girls-2). Boys respondents have a higher score in all items, then girls examinees, which means that the children do not manifested immature behavior, with some exception in girls sub-sample, when considering statements on aggressive behavior "sometimes", with higher percentage $(53.3 \%)$, then in boys respondents, which may point out on contemporary feminist gender role in society. Conducted MANOVA ( $F=14.65, p=.000)$, and DISCRA $(\mathrm{F}=14.29, \mathrm{p}=.000)$ analysis indicates a significant between «groups» difference, considering school students of different EO. The established (c.dsc) are in following items: SBH32 
(0.823), SBH33 (0.143), SBH31 (0.052), on the level of significance: $(0.000,0.005,0.009$, respectively). Hom. (\%): GRE-1: 14/15 (93.3\%); SRB-2: 23/30 (76.7\%). Ctrb. (\%): AF-32 (80.845), AG-33 (14.05), AE-31 (5.11).

$\mathrm{C}_{10}$ - The Scale Of Family Activities And Family Relationships. The family situation is of great importance for children's health, and also is know that the child health condition can affect family relationships. With this (Q), the authors wanted to assess the level of restrictions that families experience because of their children's health. This 4-point intensity scale is designed to measure the frequency of restrictions in common family activities, which may be conditioned by the physical or emotional problems, as well as with attention disorders, and child behavior. Replies are ranging from "often" to "never", when the low score points out that the child health often has disturb the family activities, or it cause the family tensions, while high score means that child health never produce tensions, nor disturb ordinary activities. For the assessment of family connections has been provided one item, where respondent should answer how well the members their family agree among themselves, whereas the responses vary from "excellent" to "bad". The low score means that the ability to connections is assessed as «bad», whereas the high score points out on positive family connections ability.

\begin{tabular}{|c|c|c|c|c|}
\hline \multicolumn{5}{|c|}{ Table 10. The Scale of Family Activities and Relationships - FAR (34-36) } \\
\hline \multicolumn{5}{|c|}{ (AH-34) How the student's environment globally estimated children's behavior? } \\
\hline SAMPLES/Sub-samples & $S R B-2(N=30)$ & Boys-2 ( $n=15)$ & Girls-2 (n=15) & GRE-1 $(N=15)$ \\
\hline Excellent & $53.6 \%(4)^{*}$ & $46.1 \%$ & $60 \%$ & $6.7 \%$ \\
\hline Very good & $28.6 \%$ & $38.5 \%$ & $20 \%$ & $60 \%(3)^{*}$ \\
\hline Good & $10.7 \%$ & $15.4 \%$ & $6.7 \%$ & $33.3 \%$ \\
\hline Poor & $7.1 \%$ & $(-)$ & $13.3 \%$ & $(-)$ \\
\hline \multicolumn{5}{|c|}{ (AI-35) How the child's health disrupted normal family activities, cause family tension? } \\
\hline SAMPLES/Sub-samples & SRB-2 $(N=30)$ & Boys-2 $(n=15)$ & Girls-2 (n=15) & GRE-1 (N=15) \\
\hline Never & $75 \%(4)^{*}$ & $85 \%$ & $66.7 \%$ & $6.7 \%$ \\
\hline Sometimes & $17.8 \%$ & $15 \%$ & $20 \%$ & $86.7 \%(3)^{*}$ \\
\hline Often & $3.6 \%$ & $(-)$ & $6.7 \%$ & $6.7 \%$ \\
\hline Always & $3.6 \%$ & $(-)$ & $6.7 \%$ & $(-)$ \\
\hline \multicolumn{5}{|c|}{ (AJ-36) How well the student's family members agree among themselves? } \\
\hline SAMPLES/Sub-samples & $S R B-2(N=30)$ & Boys-2 (n=15) & Girls-2 $(n=15)$ & GRE-1 $(N=15)$ \\
\hline Excellent & $71.5 \%(4)^{*}$ & $69.2 \%$ & $73.3 \%$ & $6.7 \%$ \\
\hline Very good & $17.8 \%$ & $23.1 \%$ & $13.3 \%$ & $40 \%(3) *$ \\
\hline Good & $7.1 \%$ & $(-)$ & $13.3 \%$ & $53.3 \%(2)^{*}$ \\
\hline Poor & $3.6 \%$ & $7.7 \%$ & $(-)$ & $(-)$ \\
\hline
\end{tabular}

Scale of Family Activities and Relationships (SFAR) presents relative values within items. Provided statements point out on some numerical gender differences between HC sub-samples (Boys-2; Girls-2). Girls examinees, in contrary to boys respondents, have a majority of higher scores in all items, except in (AI-35), where girls examinees opted within all statements modalities. Conducted MANOVA $(\mathrm{F}=18.498, \mathrm{p}=.000)$, and DISCRA $(\mathrm{F}=18.046, \mathrm{p}=.000)$ analysis indicates on a significant between "groups» difference, considering school students of different EO. The established (c.dsc) are in following items: SFAR36 (0.682), SFAR35 (0.400), SFAR34 (0.029), on the level of significance: $(0.000$, 0.000, 0.001, respectively). Hom. (\%): GRE-1: 14/15 (93.3\%); SRB-2: 27/30 (90\%). Ctrb. (\%): AJ-36 (61.4), AI-35 (36.0), AH-34 (2.6). 
$\mathbf{C}_{11}$ - The Scale Of Change In Health - which comprise only one item. This scale registers the health changes over the previous year. Answers range up "much better now" to "much worse now", so that the low score tells of deterioration, and the high score on the improvement of health.

\begin{tabular}{|l|l|l|l|l|}
\hline \multicolumn{5}{|c|}{ Table 11. The Scale of Health Change - L-SHC (37) } \\
\hline (AK-37)How the student assesses health changes over the last year? \\
\hline SAMPLES/Sub-samples & SRB-2 (N=30) & Boys-2 (n=15) & Girls-2 (n=15) & GRE-1 (N=15) \\
\hline much better now & $\mathbf{5 3 . 5 \%}(\mathbf{4}) *$ & $\mathbf{7 6 . 9} \%$ & $33.3 \%$ & $20 \%$ \\
\hline improvement tendency & $39.3 \%$ & $23.1 \%$ & $53.3 \%$ & $80 \%(3) *$ \\
\hline tendency of worsening & $3.6 \%$ & $(-)$ & $6.7 \%$ & $(-)$ \\
\hline much worse now & $3.6 \%$ & $(-)$ & $6.7 \%$ & $(-)$ \\
\hline
\end{tabular}

Scale of Health Change (SHC). Provided statements range up "much better now" as was in Boys sub-sample (76.9\%), to "tendency of improvement" in Girls sub-sample $(53.3 \%)$ of the HC school students. These options point out on some gender differences in this segment of scale, which evaluate the change in health.

Conducted MANOVA $(\mathrm{F}=7.43, \mathrm{p}=.009)$, and DISCRA $(\mathrm{F}=7.259, \mathrm{p}=.010)$ analysis indicates on a significant between "groups» differences, considering school students of different EO. The established (c.dsc) in item SHC37 is (0.173), with significance (0.010). Hom. (\%): GRE-1: 12/15 (80\%); SRB-2: 18/30 (60\%), Ctrb.\% AK-37 (100.0).

\section{Conclusion}

Based on the conducted mathematical-statistical procedures, and the comparative analysis of the study results and their interpretation, it can be formulated the following conclusions, which indicates on the estimation of the significant differences.

To the between «groups» differences, mostly have contributed the characteristics and homogeneity of the groups of different ethnic origins, concerning the items of particular segments, the frequency of responses, i.e., a different opting for individual statements modalities of items.

Respondents of GRE-1 school students have lower variability of the statements, which were of the moderate intensity of modalities $\left(2^{*}-3^{*}\right)$, while the respondents of SRB-2 school students, with one exception $(1 *)$, opted for the highest intensity of statements modality $\left(4^{*}\right)$ for the most items, within particular segments, which has significantly contributed to the established differences.

Based on the elaborated MANOVA and DISCRA comparative analyses, and the obtained values (F; p), must be rejected the hypothesis $\mathrm{H}_{1}$ and $\mathrm{H}_{2}$ in all segments of the $\boldsymbol{Q}$, and accepted the alternative hypothesis $A_{1}$, and $A_{2}$, which means that there is a difference, and clearly defined border between "groups" of respondents (GRE-1; SRB-2) in all segments of $\boldsymbol{Q}$, which assesses the Quality of life, Health and Social Wellness in upper elementary school students, when considering "groups" of different ethnic origins. 


\section{References}

Kvrgić, S. (2001). The quality of life of school children and youth. Kvalitet života školske dece $\mathrm{i}$ omladine. (in Serbian), Belgrade: Andrejević Foundation, TODRA.

Popović, R. (2015). Physical education of children with medical conditions. International Scientific Conference "FIS Communications 2015" in Physical Education, Sports and Recreation. Book of Proceedings, pp. 210-216. University of Nis, Faculty of Sport and Physical Education.

Popović, J., Popović, R., Mutavdžić, V. (2016). The Social Characteristics of Folklore Dancers and Their Family Members in Some Manifest Stratification Variables: Gender Differences. Slovak Journal of Sport Science, Vol. 1, no. 2: 15-27. ISSN 2453-7659.

Popović, J., Popović, R., Mutavdžić, V. (2017). A Selective Review of Social Status Characteristics of Folk Dance Dancers and Their Family Members with Presentation of Gender Specificities. International Journal of Education, Culture and Society. Vol. 2(3849), doi:10.11648/j.ijecs.20170202.11

Popović, R., Samouilidou, E., Dolga, M. (2015). The quality of life of school age children and youth. FSFV- Conference, Belgrade-2015. Book of Proceedings (pp. 508522), University of Belgrade, Faculty of Sport and Physical Education. ISBN 978-8689773-14-9.

Samouilidou, A.E. (2004). Stimulation of the motor development of children with mental retardation. Stimulacija motorickog razvoja dece sa mentalnom retardacijom (in Serbian) Belgrade: Andrejević Foundation, TODRA.

(2007). Dictionary of Sociology. Sociološki rečnik (in Serbian), Eds: A. Mimica, M. Bogdanović. Belgrade: Zavod za udžbenike i nastavna sredstva - Institute for the textbooks and educational tools.

Taras, H. (2005). Physical activity and student performance at school. Journal of School Health, 75 (6), 214-218. 